\title{
AN EMPIRICIST FRAMEWORK FOR TQM IMPLEMENTATION IN CONSTRUCTION COMPANIES
}

Tas Yong $\mathrm{KOH}^{1}$ and Sui Pheng LOW ${ }^{2}$

${ }^{1}$ Ph.D. candidate, Dept. of Real Estate and Construction, University of Hong Kong, Rm. 501, Knowles Building, HKU, Pokfulam Rd., Hong Kong (corresponding author). E-email: koolfern@gmail.com

${ }^{2}$ Professor, Dept. of Building, School of Design and Environment, National University of Singapore, 4, Architecture Drive, Singapore 117566. E-mail: bdglowsp@nus.edu.sg 


\title{
AN EMPIRICIST FRAMEWORK FOR TQM IMPLEMENTATION IN CONSTRUCTION COMPANIES
}

\begin{abstract}
As a management philosophy, total quality management (TQM) is implemented differently in firms. This study investigates the implementation level and the types of TQM practices adopted in construction companies. Eight elements had been identified from both organizational/management- and construction-related studies to represent the TQM spirit. These elements are top management leadership, customer management, people management, supplier management, quality information management, process management, organizational learning, and continual improvement. A questionnaire survey was conducted to solicit the implementation level of the identified TQM elements. The survey findings indicate that customer, process management, and top management leadership were implemented at a higher level than the remaining elements with quality information management implemented at the lowest level. Important practices that constitute each element were also identified. Based on the findings, we propose a TQM implementation framework for construction companies.
\end{abstract}

Subject headings: Total Quality Management; contractor; TQM framework; Singapore 


\section{Introduction}

Studies on the application of Total Quality Management (TQM) in construction can be categorized into three themes. The first theme is embodied in the works on the application of TQM principles and elements to construction processes (e.g. Delgado-Hernandez and Aspinwall 2008; Koh and Low 2008; Strange and Vaughan 1993; Chase 1993; Graves 1993; Burati et al.1992). The second theme involves the development of process model in initiating and subsequent implementation of TQM programs in construction organizations (e.g. Elghamrawy and Shibayama 2008; Low and Teo 2004; Ahmad and Sein 1997; Arditi and Gunaydin 1997; Federle and Chase 1993; Burati and Oswald 1993). The third theme revolves around the problems and impediments in the implementation of TQM (Low and Teo 2004; Abdul-Aziz 2002; McIntyre and Kirschenman 2000; Shammas-Toma et al. 1998; Demski 1993; Rounds and Chi 1985) as a result of construction peculiarities.

While the adversarial relations, opportunistic behaviors, and distributive attitudes (Rooke et al. 2003) prevalent within the construction fraternity have posed many challenges to the implementation of TQM, the simultaneous mechanistic, organismic, and cultural nature of TQM (Spencer 1994) have accorded its application in construction as evident in the first two themes of studies. TQM, as a management philosophy (Roney 1997), is practical oriented towards the management of organization. It can therefore be applied in a wide range of operations. 
As part of a wider study to investigate the relationships between local construction companies' organizational culture and their TQM practices, the present study aims to explore the practices adopted by construction firms in Singapore under various TQM elements. In so doing, we hope to contribute to the development of both the first and second themes while providing some insights into the behavioral and methodological aspects of organization's management practices under TQM. Based on the literature review and data analysis, a TQM implementation framework is proposed.

\section{The TQM Elements}

The synthesis of the philosophies, principles, and interventions of the TQM proponents in both construction- and non-construction-related studies has yielded eight possible elements for the TQM implementation. These elements are (1) top management leadership, (2) customer management, (3) people management, (4) supplier management, (5) quality information management, (6) process management, (7) learning, and (8) continual improvement. Table 1 presents the comparisons of these studies.

The goals of TQM are to establish quality enhancement as an organizational dominant priority and to improve organizational effectiveness (Spencer 1994). The process of producing quality work and improvement must start with the commitment of the senior management as they are responsible to create the systems and infrastructure of production (construction). The top management's roles are mainly manifested in its leadership, commitment, and involvement in driving TQM implementation. Top management creates organizational quality values and goals (Ahire et al. 1996). At the operational level, the commitment and 
leadership involve the acceptance of quality evaluation and responsibility by the project manager and other head of departments, the institution of comprehensive quality planning, the emphasis of the importance of quality in relation to cost and schedule of construction (cf. Saraph et al. 1989), the provision of adequate resources for quality management, the communication on the quality intent of the organization (Delgado-Hernandez and Aspinwall 2005; Chase 1993).

Customer focus and management is the anchor point principle of TQM (Chiles and Choi 2000). Customer focus is expressed as the production of goods or services that fulfill the customer needs. In construction, this refers to the achievement of project requirements in terms of technical specification and client's satisfaction. In addition, it also involves the maintenance of a close relationship with the client, embracing client focus in the quality management activities (Ahire et al. 1996), and developing strategic alliance with the customer (Low and Tan 2002). At the operational level, TQM envisions the promotion of cooperative working relations among all parties into the formation of a joint team (Burati et al 1992). This implies a lessened emphasis and reliance on contractual execution favoring instead a relational approach among parties. Customer focus also involves the communication and feedback processes on the client's concerns and satisfaction. This information can then be used for both internal and external benchmarkings (Black and Porter 1996). Initiatives peculiar to construction include impressing the "customer’s customer” by establishing a good relationship with the end buyers / occupiers in the post-construction phase, and the provision of differentiated services or solution to the client's project. 
The element of people management entails the collaboration between managers and non-managers, and between customers and suppliers. This element is related to the systems view of organization and is based on benefits that can potentially be derived through partnership among the parties (Dean and Bowen 1994). People management includes employee involvement in quality management in terms of employees' participation in quality decision. This provides the basis on the use of cross-functional quality improvement teams (Ahire et al. 1996) and the provision of feedback on their performance. Recruitment and selection of employee based on their ability to work in a team and problem solving skills (Flynn et al. 1994) are another consideration as TQM thrives in teamwork environment, and the alignment of human resource management with the organization's quality performance plan (Black and Porter 1996). In addition, empowerment of employees is emphasized whereby employees are encouraged to inspect their own work and fix any quality problems with the provision of supporting framework and necessary resources.

The element of supplier management stems from the recognition that firms rely on one another for resources allocation. Cooperation between a firm and its suppliers thrives on the cooperative interdependence (Anderson et al. 1994). This interdependence is particularly salient in construction for subcontracting and various supply arrangements are pervasive in construction. Quality of the facility built by the main contractor is directly related to the quality of resources and works provided by various parties (designers, suppliers, and subcontractors). Supplier management entails the creation of supplier partnerships involving the selection of suppliers on the basis of quality instead of solely on price (Saraph et 
al. 1989), reliance on reasonably few suppliers / subcontractors, embracing the suppliers / subcontractors in the construction processes, and the development of a long-term relationship promoting an interdependent and cooperative attitude.

The element of quality information management originates from the principle of management by fact. It concerns the systematic collection of data at every point of the construction process, improvement, and problem-solving activities. The data and information collected are then used to guide decisions, provide a means of learning, and help keep processes in control (Flynn et al. 1994).. The issues involved are the usage, availability, and timeliness of the quality information. The quality information used as feedback to employees on their performance facilitates learning and maintains their quality oriented behavior (Ashford and Cummings 1983).

Construction operation can be viewed as a set of horizontal and interlinked processes. The quality of intermediate product/service and final built facility depends on the quality of the processes by which the product is produced. As uncontrolled variance in processes often causes quality problem, it is essential to analyse and control the variance (Hackman and Wagemen 1995). Process management involves the inclusion of quality measures in the construction processes, and continuous monitoring and control of those processes (Claver et al 2002). The implementation of in-process and final inspection, review, and the design of the construction process to be "fool-proof" to minimize worker's errors are essential in ensuring quality in the process outcome.

Learning is central to the improvement of existing processes and the discovery of novel processes. Learning ensures mistakes are not repeated and more 
importantly the learning that is applied to the existing processes (the process task knowledge) and that of foundational knowledge on organizational systems (the profound knowledge) stimulates continuous improvement (Anderson et al 1994). The literature on organizational learning has illuminated the point. Two domains are seen as necessary to promote such learning: one involves the factors for double-loop learning, the other concerns the learning dimensions (Kululanga et al 2002). While double-loop learning focuses on errors detection and correction such that it modifies an organization's implicit norms and objectives (Love et al 2000), learning dimensions are strategies that an organization adopts to imbibe knowledge from its internal and external environments (Kululanga et al 2002).

The element of continual improvement involves a commitment to constantly examine the technical and administrative processes for better methods. By improving these processes, an organization can continue to meet the increasing expectations of customer (Dean and Bowen 1994). Continual improvement aims to enhance the reliability and control of performance of the construction system. It capitalizes on learning so that organization can continue to develop new skills and capabilities (Sitkim et al 1994). To facilitate improvements, an organizational structure is required. The structure involves a technical system that helps to identify and study key processes for improvement, process control mechanism, the assessment for improvement, the mechanism of analysing cost data to gauge performance, and benchmarking activities (Black and Porter 1996).

\section{Methods}

\section{Research Design and Sampling}


A sample survey was chosen as the research design for this study. The aim of the research to study the practices adopted by local construction companies entails a sampling consideration that calls for a certain level of sophistication in the quality management practices of those firms. Two interrelated issues are of concern. First, for the purpose of representation, the contractors chosen to participate in the study must collectively be the main players in the local construction industry (Low and Fong 2002). This study had classified the contractors with grades A1 to A2 as large contractors, and B1 to B2 as medium size contractors. Accordingly, these contractors were taken as playing significant role in the industry and were included as sample for the study.

Second, the inclusion of medium- to large-sized contractors is in line with Saraph et al's (1989) recommendation as the level of quality management implementation in these companies (contractors) is perceived to be relatively more sophisticated than their smaller counterparts. Saraph et al (1989) have asserted that quality management practices of small firms are likely to be less sophisticated or highly variable.

Based on the sampling requirements of the wider study, 145 local contractors were indentified to participate in the study. Because of the small sample size, all of the 145 contractors were invited to participate in the survey. The target respondents were the contractor's managerial (general manager, quality systems manager, contracts manager, etc.) or professional personnel (quality engineer, quantity survey, project engineer, etc.) as these are likely to be the "thought" leaders with respect to quality management within the company (Saraph et al. 1989). In addition, all the contractors are ISO9001: 2000 certified, signifying that 
there exists a properly structured quality framework among the companies as the ISO Standards connotes the prevalence of some TQM elements in the companies' quality management systems.

\section{Questionnaire Design and Administration}

The questionnaire consists of two parts. The information of the respondent's company, i.e. the company's profile, constitutes the first part. The TQM implementation constitutes the second part.

The section on TQM solicits the information on the company's TQM implementation level. This section was eclectically constructed with reference to the published empirical research on TQM implementation (Claver et al 2002; Kululanga et al 2002; Low and Tan 2002; Ahire et al 1996; Black and Porter 1996; Flynn et al 1994; Saraph et al 1989). Items that fall into one of the eight TQM elements identified and are relevant to the construction context were first extracted from the literature. As the instruments employed in the literature were largely developed in the manufacturing and service environment, modifications were performed on the instruments in terms of couching the statements in the questionnaire to the manner befitting construction contexts.

Each item in the questionnaire describes a practice that requires the respondent to rate the level of current TQM implementation in term of the "degree of practice" in a 1 to 5 Likert-like scale; "1" being "very lowly practiced" to "5" being “very highly practices”. The data collection phase was conducted during July 2003 through to February 2004. 56 responses were received and used for the analyses.

\section{The TQM Practices}




\section{Characteristics of Respondents and Companies}

$31 \%$ of the respondents were director and general manager; $40 \%$ senior manager, project, contracts, and quality manager; and 29\% assistant manager, executive, and engineer. For the scope of the business, all of the contractors were active in more than one project type with more than two-third of contractors engaged in residential projects while over half were engaged in commercial projects. For the staff strength, $66 \%$ of the firms had less than 50 permanent staffs, $27 \%$ between 50 to 150 staffs, only 7\% had more than 150 staffs. Almost similar proportion of firms had annual turnover of less than $\mathrm{S} \$ 50$ millions (68\%), between $\mathrm{S} \$ 50$ millions and S\$150 millions (25\%), and over S\$150 millions (7\%). It can be seen that majority of the firms were of medium size. The Building and Construction Authority (BCA) registration grades further justifies the observation. Majority of the contractors were from the "medium" grades of B1 (32\%) and B2 (36\%). 16\% each for "large" firms were recorded for both A1 and A2 grades. As for the ISO9001: 2000 certification, majority of the companies were certified in the years 2002 and 2003 (combined 64\%) indicating the "last minute rush" to getting certified before the end of 2003 where the mandatory certification comes into effect. This trend also suggests that the companies have relatively short experience with the TQM-like quality management system embodied in the Standards.

\section{Overall Level of TQM Practices}

The mean scores on the level of TQM implementation are shown in Table 2. The mean scores on the level of implementation range from 3.01 to 3.66. 
The elements of customer management (3.60) and process management (3.66), and to certain extent, top management leadership (3.53) are implemented "moderately-highly" toward the implementation level of 4 . The element of process management, being the most highly implemented element, is in line with the traditionally acquainted hard techniques adopted by contractors in controlling their construction operations.

The second highest mean score of 3.60 for customer management may be interpreted as the increasing recognition on the more closely embracement of project client in the construction operation. This recognition is in line with the consistent emphasis on the necessity to integrate the project delivery process through partnering and alliancing (Dainty et al. 2001) and the acknowledgement of partnering as a potentially important way to improve construction project performance (Bresnen and Marshall 2000a). In addition, the increasing realization on the possibility of achieving a "win-win situation" for both the contractors and clients from the performance benefits of collaboration (Bresnen and Marshall 2000b) may have also resulted in such a phenomenon. In this respect, the customer management element (and other externally oriented elements such as supplier management, organizational learning, and continual improvement) can be used as catalyst for a construction firm to be more in tuned with partnering initiatives when engaged in a project. Indeed, TQM, as a unitary organizational management practice, may be viewed as antecedent to partnering, as an interorganizational management practice, in a project coalition (cf. Tang et al. 2009).

The third highest mean score of 3.53 for the element of top management leadership is a rather comforting observation as the senior management leadership 
and commitment are seen as the prerequisite for TQM implementation. The result has demonstrated that local contractors do accord some degrees of leadership and commitment in quality management.

The element of quality information management has the lowest mean score of 3.01. In addition, it has the highest standard deviation of 0.70 . This observation has provided evidence to support the comment on the lack of proper and structured information management in the construction fraternity. The high dispersion of the mean score indicates that this element records a rather vast range of level of implementation. This vacillation may suggest the inconsistency of implementation level among the contractors, and that the area of quality information management is still in need of acknowledgement and improvement.

We move now to examine individual element of the formation of its content from a large set of items constituting the elements. With factor analysis performed on each element, we derive a reduced set of factors from the original set of items under each element. We performed factor analyses on the basis of retaining factors with eigenvalues of greater than 1, adopting Varimax orthogonal rotation method (Field 2000), taking the factor loading of 0.7 or above to be significant for interpretation due to the small sample size (Hair et al. 1998, p. 112), and retaining factors that account for at least 60\% (and lesser in certain instances) of the variance explained (Hair et al. 1998, p. 104). The results of factor analyses for all the TQM elements are presented in Table 3.

\section{Customer Management}

Factor 1: Provision of differentiated services to client. The provision of differentiated services to client may indicate the extra and different services the 
contractors extend to the client in the form of alternative design or work package proposal which result in cost saving to the client. Differentiated services rendered also include attending actively to the client's requirements.

Factor 2: Maintenance of close contact with client. This factor bears close resemblance to part of the characteristics of Factor 1 . The maintenance of close contact with the client implies being attentive to the client. In addition, capturing of client satisfaction and the dissemination of the information to various project personnel constitutes part of the close contact.

Factor 3: Provision of indirect service. Customer management and customer care also come in the form of informal get-together session with the client's personnel. Small lunch party may epitomize this session. In addition, indirect service can also be in the form of attending attentively to the client's customers. This is evident in most of the residential projects where the contractors often extend the extra services to the end-purchaser of a residential unit.

\section{Top Management Leadership}

Factor 1: Comprehensive communication and development of quality policy and plan. This factor includes the deployment of quality policies, goals, and objectives. The management, heads of department (HODs), and project managers provide leadership by participating in the quality improvement work, and encouraging employee’s participation in quality decisions.

Factor 2: Acculturation of a company-wide quality culture. Supplementing the first factor, the promotion of a company-wide culture involves embracing the long-term view on quality and the instillation of a culture of evaluating the HODs on their quality performance, of communicating and involving in quality matters, 
of promoting quality awareness, and of encouraging employees to actively participate in change efforts. The main ideas appear to be the inculcation of a culture that emphasizes employees’ participation and leadership by example.

Factor 3: Treating quality as more important than schedule and cost. This factor represents the mentality underpinning the previous two factors. The treatment of quality as an important issue is likely to be cascaded through the management's leadership and the daily operational domains. Additional data may have shown support on this observation with the provision of adequate resources towards efforts to improve quality (with a factor loading of 0.568).

\section{People Management}

Factor 1: Constant communication and employees' participation in quality efforts. The issue on communication includes the promotion of quality awareness, the provision of feedback and management's recognition of the employees' quality performance. On participation, in addition to the participation of supervisory personnel, participation of non-supervisory staff (e.g. quantity surveyor) was also encouraged by the management.

Factor 2: Employee's empowerment. Employees' empowerment involves the encouragement for workers to inspect their own works and fix any problems that may arise accordingly. To achieve this, the management provides resources (e.g. sufficient materials and technical assistance) that are necessary to fix the problems. Another dimension of employees' empowerment is the use of crossfunctional teams and the encouragement of participation from all members within the team. An extra item subsumed under this factor is the consideration of the company human resource management with the development of the company's 
quality performance plans. An inspection of the factor solution also reveals that accountability for quality performance by employee, although with only moderately significant factor loading, is an issue of concern to the management possibly in commensuration with empowerment.

Factor 3: Employee's selection based on problem-solving ability. In addition to the problem-solving ability, employee's selection is also based on the employee's ability to work in a team environment. Indeed, the importance of teamwork in construction operation is also underscored by the emphasis not only on the selection that is based on ability to work in a team but also the promotion of training of employees in teamworking.

\section{Process Management}

Factor 1: Continuous quality control on construction processes. Two issues are of concern. The first is the traditional inspection and checking of construction processes at both intermediate and final stages of the works. The inspection has also resulted in the prevention of faulty works from being worked on in subsequent processes. The second issue concerns the incorporation of quality measures in the construction processes. This includes developing the construction schedule with the focus on quality and the maintenance of schedule stability to minimize disruption on the production of quality work.

Factor 2: Provision of clear process instructions. The clear instruction may be epitomized in the form of a well-structured and clear method statement, work flow, and inspection-and-test plan (ITP). Often, a work sample is used to convey the requirements on the standards and to demonstrate good work practices. 
Related to this practice (also the previous factor) is the design of "fool-proof" construction processes so that human errors can be minimized.

\section{Continual Improvement}

Factor 1: Adopt process assessment and improvement. The adoption of processes assessment and improvement entails the assessment of construction processes in terms of both cost and process performance. Improvement efforts are then formulated based on these assessments. However, while the analysis of performance and cost data is relatively highly practiced (with mean of 3.55), the remaining assessment measures appear to be only moderately practiced. A supplementary practice that is subsumed under this factor with moderate factor loading is the use of specific organizational structure (e.g. cross-functional teams) to support quality improvement.

Factor 2: External benchmarking. External benchmarking includes the promotion of quality improvement with outside groups, benchmarking against direct competitors and non-competing organizations. The promotion of quality improvement with the outside group frequently involves the cooperation with subcontractors, and materials and system suppliers for improvement initiatives while benchmarking against direct competitors often entails emulating successful practices adopted by other contractors. Although these practices have emerged to form one factor, their mean ratings indicate that these are only moderate to lowly implemented practices (mean ratings range from 2.79 to 3.30 ).

\section{Quality Information Management}

Factor 1: Structured data gathering and usage. This factor embraces two issues. First is the issue of data gathering. Data gathering involves the use of structured 
procedures to ensure reliability and improvement of data gathering. A well structured checklist incorporating the acceptance criteria, inspection procedures, frequency count and listing of defective items are few such practices. The second concerns the issue of data usage. The quality data is used to evaluate the performance of supervisors and managers. It is used to manage quality attainment. Supplementary to this factor is the dissemination of quality data. The data is disseminated in a timely manner to site. The distribution of quality data to dailyrated workers, although part of the factor, is however lowly practiced perhaps due mainly to the perceived low level of appreciation of such data by the workers.

Factor 2: Use of statistical quality control. The two items under this factor, although part of the factor, are both lowly practiced (evident by their low mean rating). Their formation into one factor perhaps only indicates that they share the same nature and are consistently and uniformly rated. Nevertheless, the data does imply a certain degree of practice on statistical quality control. The most commonly used statistical controls appear to be the tally chart and frequency counts.

Factor 3: Provision of quality data at operational level. This factor is related to the supplementary items of Factor 1, that of data dissemination. In this factor, the issue of data dissemination has become the main contributor to the formation of the factor. However, referring to its mean rating, this item is only moderately practiced. This situation is echoed in the even lower mean rating on the practice of making the quality data available to the client. This observation may suggest the management's somewhat reserved attitude in disclosing the quality-related data to the operational level, let alone to the client. 


\section{Supplier Management}

Factor 1: Close and long-term suppliers/subcontractors relationship. Factor 1 embraces three issues. On the issue of closeness with the suppliers/subcontractors, the close cooperation is manifested in the involvement of suppliers/subcontractors in the development of construction processes, the provision of technical assistance and clear specification to the suppliers/subcontractors. The second issue pertains to the offer of long-term working relationship with the suppliers/subcontractors. This item is rather highly practiced as evidenced by its high mean rating. Indeed, several contractors have entered into a more strategic partnership with their suppliers/subcontractors to secure future contracts. The third issue is the assessment of suppliers/subcontractors. The assessment of suppliers/subcontractors is manifested in strict quality requirement and the suppliers/subcontractors rating system that emphasizes quality achievement. While contractors do consider several other issues (e.g. circumstantial issues like suppliers/subcontractors' exclusive network partnership with a certain client) for continuous acquaintance with the suppliers/subcontractors, these assessments do play a role in the determination of partnership on an ongoing basis.

Factor 2: Reliance on relatively few suppliers/subcontractors. Although the reliance on a few suppliers/subcontractors is the main item forming this factor, its mean rating indicates that it is only moderately practiced. The more highly practiced item is the second contributor to the factor; the rating of suppliers/subcontractors on their delivery performance. In addition, the data collected shows that suppliers/subcontractors are also rated by their financial stability. Incidentally, the selection of supplier/subcontractors based on quality 
(rather than on price or schedule) is lowly practiced. These observations appear to suggest that although contractors do rely on fewer suppliers/subcontractors, their selections however, are still very much dependent on criteria other than quality.

\section{Organizational Learning}

Factor 1: Emphasis of training and learning. The items involved range from the training for the employees to understand how the organization functions and performs, the encouragement of employees to learn the skill that benefits the organization, to the development of the environment for on-the-job training. The data also indicate the supplementary items that involve sharing of learning and knowledge at team levels. However, an inspection of the mean ratings of the items forming the factor indicates that these items are only moderately practiced suggesting that contractors are still taking a pragmatic approach to learning. They only encourage employees' learning that are directly beneficial to the company.

Factor 2: Cultivating a forward-looking mentality. This factor includes the encouragement of employees' personal mastery, mental modelling, the use of systems thinking, and the reward for innovation that leads to organizational learning. The promotion of employees’ personal mastery involves encouraging the employees to become aware of their values and visions, and to overcome those negative elements in association with the values to realize their potential (Kululanga et al 2002). Mental modelling is related to personal mastery in that it concerns the building up of a positive mindset so that obsolete values are discarded and new progressive mentality is invoked to direct their behavior. The use of systems thinking concerns the search of long-term solutions instead of addressing only symptoms of the problems (Kululanga et al 2002). Using systems 
thinking also implies the recognition of the multi-disciplinary nature and interdependency of quality problems across several operational domains. Rewarding the innovation that leads to organizational learning also contributes to the formation of this factor. Related to the rewarding of innovation is a supplementary item of putting in place a process to promote learning awareness.

It is to be noted, however, that even though the items aggregate themselves to form this factor of building "a forward-looking mentality," all of them are only lowly to moderately practised. This observation suggests that although there appear to be some level of implementation, the appreciation of this part of the organizational learning items has left much to be desired. As these few items represent the mainstay of double-loop learning (Kululanga et al 2002), the implication of such a moderate level of appreciation is that contractors are still very much operating on the single-loop learning mentality.

Factor 3: Promotion of the climate of openness. Two items contribute to the formation of this factor. The first is the promotion of the climate of openness. A supplementary item is the commitment to building a shared vision of the company. The climate of openness in the organization appears to predicate the building of shared vision in that employees must first feel at ease before they can come forward to embrace the shared sense of direction the company is moving.

The second item concerns the continuous renewal of business and construction processes. Supplementary items point to the adoption of a structured improvement strategy and the emphasis on employees' understanding of the basic processes involved in construction. It is reasonable to postulate that with the climate of 
openness, the amalgamation of these three items facilitate the learning for improvement.

\section{A Framework for TQM Implementation}

A combination of the literature review and the research data has allowed us to propose a framework for TQM implementation. The proposed framework is shown in Figure 1.

The prerequisites of an effective quality management for the production (construction) system are provided by the top management leadership and commitment. Top management acts to demonstrate the responsibility in defining and communicating the vision of a desired system that cultivate cooperation. These leadership efforts simultaneously create the organizational system, process management system, and improvement system.

The organizational system consists of the elements of customer, people, supplier, and quality information management. The organizational system concerns with internal and external cooperation as characterized by the people (internal), customer, and supplier (external) management. Internal cooperation is manifested in the element of people management with emphasis on the participation and empowerment of employee. External cooperation involves the engagement with both the client and suppliers where partnership and alliancing are practiced notwithstanding the traditional legal independence of companies, and the cultural and behavioral hindrances that are present among project participants (Love et al. 1998). These three elements not only epitomize TQM as people-centered management system, but also provide the basic catalyst for the operation of the entire system. The element of quality information management 
provides the factual basis for decision making to the people system. In addition, the information management element is also extended into other domains.

The construction processes of a contracting firm involve the quality management activities (including QA/QC activities), and project management activities (Yasamis et al. 2002). Process management focuses on managing these construction processes so that they operate as planned or within controllable variation despite workforce, material, and environmental variability. To the extent that managing technical processes inevitably involves also managing the human aspects of those processes, the amalgamation of the earlier people-centered elements with the technical element of process management is necessary for an efficient and effective production (construction) system.

Both the human and technical domains are subjected to improvement system. It is this system that enhances the construction capability of a contracting firm. Learning is critical in TQM and it represents the essence of all continual improvement schemes (Kululanga et al. 2002). The criticality of learning lies with the fact that it is through learning that organizational members at all level continually raise their capacity to improve their level of performance thereby collectively augment the capability of the firm. The application of the learning outcome, i.e. the knowledge generated through learning, engenders continual improvement. The learned knowledge is transplanted into processes where incremental changes are planned, tested, observed, and appropriately implemented to improve a particular quality dimension (Anderson et al. 1994).

It is envisioned that the concerted implementation of the TQM elements leads to quality performance which in turn engenders client satisfaction. The quality 
performance can be viewed in two levels; the corporate and the project level. The corporate quality performance represents the results of corporate strategies deployment that are manifested in the formulation of construction operations while project quality performance involves effective construction of the facility and the provision of project management services (cf. Yasamis et al. 2002). The generation of feedback provides the system performance information back into the loop to various elements that continues into the next cycle of production and improvement (Flynn et al. 1994).

\section{Conclusion}

TQM, at its fundamental level, can be viewed as having its own sets of philosophy, principles, and intervention that can be amalgamated into an integrated management system. Eight elements had been identified to operationalize the TQM spirit. The research data had shown that the implementation of these elements vacillated around the medium level. Close scrutiny of the data had, however, indicated that the elements were somewhat implemented at different levels within the medium band; customer and process management, and top management leadership were implemented at a “moderately-high” level, supplier management moderately, while the remaining four elements of people management, continual improvement, and organizational learning were implemented at the lower level with quality information management implemented at the lowest level.

From the research instrument, while each element was operationalized through a series of practices, the distillation of those practices via data analyses had enabled us to derive a reduced set of important factors that represent each 
element. The factors listed represent the main practices associated with each TQM element that practitioners can employ to start off TQM implementation in construction settings. The adoption of those practices, together with their implementation under the framework and mechanism envisioned in Figure 1, will better ensure quality performance of the contracting firm. 


\section{References}

Abdul-Aziz, A.R. (2002). "The realities of applying total quality management in the construction industry.” Strucl. Surv., 20(2), 88-96.

Ahire, S.L., Golhar, D.Y., and Waller, M.A. (1996) "Development and validation of TQM implementation constructs.” Decis. Sci., 27(1), 23-56.

Ahmad, I.U., and Sein, M.K. (1997). "Construction project teams for TQM: A factor-element impact model.” Constr. Manage. Econom., 15(5), 457-467.

Anderson, J.C., Rungtusanathan, M., and Schroeder, R.G. (1994). "A theory of quality management underlying the Deming management method." Acad. Manage. Rev., 19(3), 472-509.

Arditi, D., and Gunaydin, H.M. (1997). "Total quality management in the construction process.” Int. J. Proj. Manage., 15(4), 235-243.

Ashford, S.J., and Cummings, L.L. (1983). "Feedback as an individual resource: Personal strategies of creating information.” Organiz. Behav. Human Perf., 32(3), 370-398.

Black, S.A., and Porter, L.J. (1996). "Identification of the critical factors of TQM.” Decis. Sci., 27(1), 1-21.

Bresnen, M., and Marshall, N. (2000a). "Partnering in construction: A critical review of issues, problems and dilemmas.” Constr. Manage. Econom., 18(2), 229-237.

Bresnen, M., and Marshall, N. (2000b). "Motivation, commitment and the use of incentives in partnerships and alliances.” Constr. Manage. Econom., 18(5), 587-598.

Burati, J.L., Matthews, M.F., and Kalidindi, S.N. (1992). "Quality management organizations and techniques.” J. Constr. Eng. Manage., 118(1), 112-128.

Burati, J.L., and Oswald, T.H. (1993). "Implementing TQM in engineering and construction.” J. Manage. Eng., 9(4), 456-470.

Chase, G.W. (1993). "Effective total quality management (TQM) process for construction.” J. Manage. Eng., 9(4), 433-443.

Chiles, T.H., and Choi, T.Y. (2000). "Theorizing TQM: An Austrian and evolutionary economics interpretation.” J. Manage. Stud., 37(2), 185-212.

Claver, E., Tari, J.J., and Molina, F. (2002). “Areas of improvement in certified firms advancing towards TQM.” Int. J. Qual. Reliab. Manage., 19(8/9), 1014-1036. 
Dainty, A.R.J., Briscoe, G.H., and Millett, S.J. (2001). "Subcontractor perspectives on supply chain alliances." Constr. Manage. Econom., 19(8), 841-848.

Dean, J.W.Jr., and Bowen, D.E. (1994). "Management theory and total quality: Improving research and practice through theory development." Acad. Manage. Rev., 19(3), 392-418.

Delgado-Hernandez, D.J., and Aspinwall, E. (2005). "Improvement tools in the UK construction industry.” Constr. Manage. Econom., 23(9), 965-977.

Delgado-Hernandez, D.J., and Aspinwall, E. (2008). "A framework for building quality into construction projects - Part I.” Total Qual. Manage., 19(10), 1013-1028.

Demski, S. (1993). "Resistance to change: Why your TQM efforts may fail.” $J$. Manage. Eng., 9(4), 426-432.

Elghamrawy, T., and Shibayama, T. (2008). "Total quality management implementation in the Egyptian construction industry." J. Manage. Eng., 24(3), 156-161.

Federle, M.O., and Chase, G.W. (1993). “Applying Total Quality Management to design and construction.” J. Manage. Eng., 9(4), 357-364.

Field, A. (2000). Discovering statistics using SPSS for Windows: Advanced techniques for the beginners, Sage Publications, London.

Flynn, B.B., Schroeder, R.G., and Sakakibara, S. (1994). "A framework for quality management research and an associated measurement instrument.” $J$. Oper. Manage., 11(4), 339-366.

Graves, R. (1993). “Total quality - Does it work in engineering management?” $J$. Manage. Eng., 9(4), 444-456.

Hackman, J.R., and Wageman, R. (1995). "Total quality management: Empirical, conceptual, and practical issues.” Adm. Sci. Q., 40(2), 309-342.

Hair, J.F.J., Anderson, R.E., Tatham, R.L., and Black, W.C. (1998). Multivariate data analysis, 5th Ed., Prentice Hall, Upper Saddle Hill, NJ.

Koh, T.Y., and Low, S.P. (2008). "Organizational culture and TQM implementation in construction firms in Singapore." Constr. Manage. Econom., 26(3), 237-248.

Kululanga, G.K., Price, A.D.F., and McCaffer, R. (2002). "Empirical investigation of construction contractors' organizational learning.” J. Constr. Eng. Manage., 128(5), 385-391. 
Love, P.E.D., Gunasekaran, A., and Li, H. (1998). "Concurrent engineering: A strategy for procuring construction projects.” Int. J. Proj. Manage., 16(6), 375-383.

Love, P.E.D., Li, H., Irani, Z. and Faniran, O. (2000) "Total quality management and the learning organization: A dialogue for change in construction.” Constr. Manage. Econom., 18(3), 321-331.

Low, S.P., and Fong, E.T.W. (2002). "Preparation for ISO9001-2000 - A study of ISO9000: 1994 certified construction firms.” Constr. Manage. Econom., 20(5), 403-413.

Low, S.P., and Tan, S.L.G. (2002). "Relationship marketing: A survey of QS firms in Singapore.” Constr. Manage. Econom., 20(8), 707-721.

Low, S.P., and Teo, J.A. (2004). "Implementing Total Quality Management in construction firms.” J. Manage. Eng., 20(1), 8-15.

McIntyre, C., and Kirschenman, M. (2000). "Survey of TQM in construction industry in Upper Midwest.” J. Manage. Eng., 16(5), 67-70.

PSB. (2001). ISO 9001: 2000 interpretation guide, Singapore Productivity \& Standards Board, Singapore.

Roney, J. (1997). "Cultural implications of implementing TQM in Poland.” $J$. World Bus., 32(2), 152-168.

Rooke, J., Seymour, D., and Fellows, R. (2003) "The claims culture: A taxonomy of attitudes in the industry.” Constr. Manage. Econom., 21(2), 167-174.

Rounds, J.L., and Chi, N.Y. (1985) "Total quality management for construction.” J. Constr. Eng. Manage.., 111(2), 117-128.

Saraph, J.V., Benson, P.G., and Schroeder, R.G. (1989). "An instrument for measuring the critical factors of quality management.” Decis. Sci., 20(4), 810-829.

Shammas-Toma, M., Seymour, D., and Clark, L. (1998). "Obstacles to implementing total quality management in the UK construction industry." Constr. Manage. Econom.,16(2), 177-192.

Sitkim, S.B., Sutcliffe, K.M., and Schroeder, R.G. (1994). "Distinguishing control from learning in total quality management: A contingency perspective." Acad. Manage. Rev., 19(3), 537-564.

Spencer, B.A. (1994). "Models of organization and Total Quality Management: A comparison and critical evaluation.” Acad. Manage. Rev., 19(3), 446-471. 
Strange, P.S., and Vaughan, G.D. (1993). "TQM: A view from the playing field.” J. Manage. Eng., 9(4), 390-398.

Tang, W., Qiang, M., Duffield, C.F., Young, D.M., and Lu, Y. (2009). "Enhancing total quality management by partnering in construction." $J$. Profl. Issues Eng. Educ. Pract., 135(4), 129-171.

Yasamis, F., Arditi, D., and Mohammadi, J. (2002) “Assessing contractor quality performance.” Constr. Manage. Econom., 20(3), 211-223. 


\section{AN EMPIRICIST FRAMEWORK FOR TQM IMPLEMENTATION IN CONSTRUCTION COMPANIES}

Tas Yong $\mathrm{KOH}^{1}$ and Sui Pheng LOW ${ }^{2}$

\section{List of Tables and Figure}

Table 1. Comparisons of TQM propositions by selected authors

Table 2. Overall TQM implementation level

Table 3. Results of factor analyses for TQM elements

Fig. 1. A framework for TQM implementation

${ }^{1}$ Ph.D. candidate, Dept. of Real Estate and Construction, University of Hong Kong, Rm. 501, Knowles Building, HKU, Pokfulam Rd., Hong Kong (corresponding author). E-email: koolfern@gmail.com

${ }^{2}$ Professor, Dept. of Building, School of Design and Environment, National University of Singapore, 4, Architecture Drive, Singapore 117566. E-mail: bdglowsp@nus.edu.sg 
Table 1. Comparisons of TQM propositions by selected authors

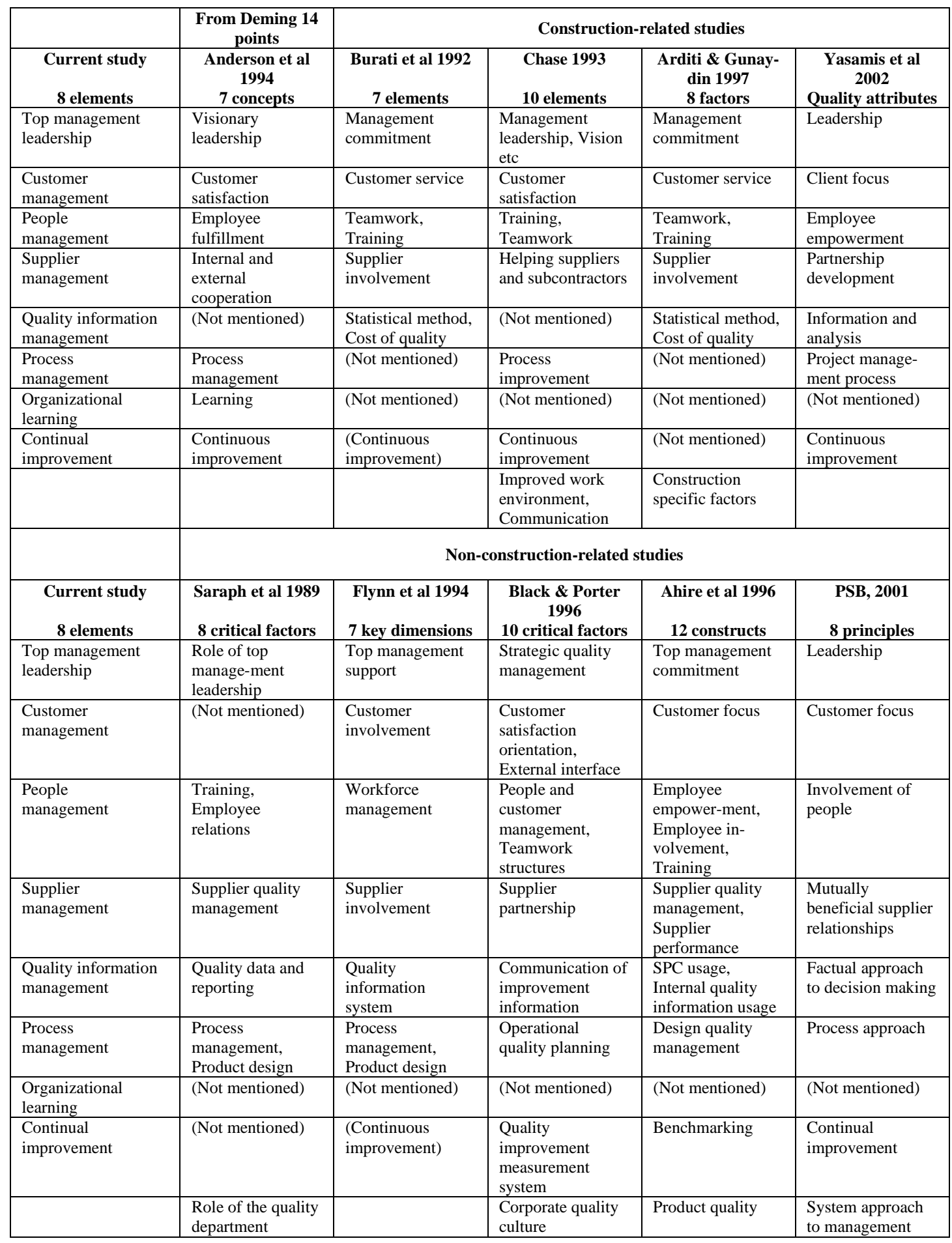


Table 2. Overall TQM implementation level

\begin{tabular}{|l|c|c|}
\hline \multicolumn{1}{|c|}{ TQM elements } & Mean & SD $^{*}$ \\
\hline Customer management & 3.60 & 0.58 \\
\hline Top management leadership & 3.53 & 0.62 \\
\hline People management & 3.31 & 0.60 \\
\hline Process management & 3.66 & 0.62 \\
\hline Continual improvement & 3.26 & 0.59 \\
\hline Quality information management & 3.01 & 0.70 \\
\hline Supplier management & 3.48 & 0.51 \\
\hline Organizational learning & 3.24 & 0.57 \\
\hline
\end{tabular}

*SD: Standard deviation 
Table 3. Results of factor analyses for TQM elements

\begin{tabular}{|c|c|c|c|c|}
\hline \multirow[b]{2}{*}{ Item description } & \multirow[b]{2}{*}{ Mean } & \multicolumn{3}{|c|}{ Factor } \\
\hline & & 1 & 2 & 3 \\
\hline \\
\hline \multicolumn{5}{|c|}{ (Cronbach alpha: 0.93; individual item KMO range: 0.707 to 0.939; Bartlett's test: 0.000 ) } \\
\hline Provision of differentiated services & 3.34 & 0.845 & & \\
\hline Process to listen and solve client's complaints & 3.52 & 0.745 & & \\
\hline Maintain close contact with client & 4.00 & & 0.814 & \\
\hline Provide client's complaints summary to Project Manager & 3.68 & & 0.810 & \\
\hline Solicit feedback from client & 3.84 & & 0.739 & \\
\hline Implement client informal get-together session & 2.98 & & & 0.844 \\
\hline \multirow[t]{3}{*}{ Establish good relationship with end-purchaser } & 3.32 & & & 0.782 \\
\hline & \% of var. & 26.361 & 22.685 & 16.099 \\
\hline & Cum. \% & 26.361 & 49.046 & 65.145 \\
\hline \multicolumn{5}{|c|}{ Top management leadership } \\
\hline \multicolumn{5}{|c|}{ (Cronbach alpha: 0.96; individual item KMO range: 0.683 to 0.964; Bartlett's test: 0.000 ) } \\
\hline Implement comprehensive quality goal-setting & 3.48 & 0.834 & & \\
\hline Heads have objective for quality performance & 3.82 & 0.789 & & \\
\hline Ensure quality goals and policies are understood & 3.68 & 0.752 & & \\
\hline Implement comprehensive quality plan & 3.41 & 0.702 & & \\
\hline Encourage company-wide quality culture & 3.41 & & 0.723 & \\
\hline Consider quality in developing long-term goals & 3.54 & & 0.709 & \\
\hline Heads responsible for quality performance & 3.88 & & 0.705 & \\
\hline Heads evaluated for quality performance & 3.63 & & 0.703 & \\
\hline Management views quality more important than schedule & 2.89 & & & 0.857 \\
\hline \multirow{3}{*}{ Management views quality more important than cost } & 3.45 & & & 0.796 \\
\hline & \% of var. & 27.138 & 25.755 & 17.510 \\
\hline & Cum. \% & 27.138 & 52.892 & 70.402 \\
\hline \multicolumn{5}{|c|}{ People management } \\
\hline \multicolumn{5}{|c|}{ (Cronbach alpha: 0.94; individual item KMO range: 0.756 to 0.935; Bartlett's test: 0.000 ) } \\
\hline Promote quality awareness on continuous basis & 3.45 & 0.833 & & \\
\hline Provide feedback to employee on performance & 3.20 & 0.782 & & \\
\hline Encourage participation by non-supervisory staff & 3.23 & 0.770 & & \\
\hline Encourage workers to fix quality problems & 3.18 & & 0.852 & \\
\hline Encourage workers to inspect own works & 3.27 & & 0.840 & \\
\hline Provide resources for workers to fix quality problems & 3.23 & & 0.710 & \\
\hline Use cross-functional team to solve problems & 3.14 & & 0.704 & \\
\hline \multirow[t]{3}{*}{ Base employees selection on ability in problem-solving } & 3.61 & & & 0.845 \\
\hline & \% of var. & 25.319 & 22.522 & 20.292 \\
\hline & Cum. \% & 25.319 & 47.842 & 68.134 \\
\hline \multirow{2}{*}{\multicolumn{5}{|c|}{$\begin{array}{l}\text { Process manaqement } \\
\text { (Cronbach alpha: } 0.94 ; \text { individual item KMO range: } 0.756 \text { to } 0.935 ; \text { Bartlett's test: } 0.000 \text { ) }\end{array}$}} \\
\hline & \multicolumn{4}{|c|}{ (Cronbach alpha: 0.94; individual item KMO range: 0.756 to 0.935; Bartlett's test: 0.000 ) } \\
\hline Conduct process inspection, review, \& checking & 3.77 & 0.905 & & \\
\hline Conduct final inspection, review, and checking & 3.80 & 0.888 & & \\
\hline Prevent faulty works from being worked on & 3.64 & 0.844 & & \\
\hline Include quality measures in construction processes & 3.63 & 0.726 & & \\
\hline Implement continuous control of construction processes & 3.71 & 0.715 & & \\
\hline Provide clear construction process instruction & 3.57 & & 0.910 & \\
\hline Design construction processes to be fool-proof & 3.39 & & 0.844 & \\
\hline \multirow[t]{3}{*}{ Emphasize good housekeeping on site } & 3.75 & & 0.751 & \\
\hline & \% of var. & 41.973 & 32.479 & \\
\hline & Cum. \% & 41.973 & 74.452 & \\
\hline \multicolumn{5}{|c|}{ Continual improvement } \\
\hline Analyze performance and cost data to support improvement & 3.55 & 0.871 & & \\
\hline Assess improvement of processes, practices, and services & 3.48 & 0.859 & & \\
\hline $\begin{array}{l}\text { Adopt process control \& improve core processes with } \\
\text { design }\end{array}$ & 3.23 & 0.761 & & \\
\hline Adopt programs to find time cost losses in all processes & 3.23 & 0.735 & & \\
\hline Promote quality improvement with outside groups & 3.14 & & 0.845 & \\
\hline Benchmark against direct competitors & 3.13 & & 0.798 & \\
\hline Benchmark against non-competing organizations & 2.79 & & 0.742 & \\
\hline Use techniques to identify key processes for improvement & 3.30 & & 0.709 & \\
\hline & \% of var. & 34.285 & 31.694 & \\
\hline & Cum. \% & 34.285 & 65.978 & \\
\hline
\end{tabular}


Table 3. Results of factor analyses for TQM elements (cont'd)

\begin{tabular}{|c|c|c|c|c|}
\hline \multirow[b]{2}{*}{ Item description } & \multirow[b]{2}{*}{ Mean } & \multicolumn{3}{|c|}{ Factor } \\
\hline & & 1 & 2 & 3 \\
\hline \\
\hline \multicolumn{5}{|c|}{ (Cronbach alpha: 0.93; individual item KMO range: 0.728 to 0.933; Bartlett's test: 0.000 ) } \\
\hline Use quality data to evaluate supervisors \& managers & 3.16 & 0.863 & & \\
\hline Use quality data to manage quality & 3.30 & 0.751 & & \\
\hline Implement structured data gathering to ensure reliability & 3.20 & 0.731 & & \\
\hline Furnish quality data to daily-rated workers & 2.57 & 0.716 & & \\
\hline Equipment under statistical quality control & 2.86 & & 0.860 & \\
\hline Use statistical quality control to reduce variance in process & 2.79 & & 0.849 & \\
\hline Make available quality data to project site & 3.11 & & & 0.870 \\
\hline \multirow[t]{3}{*}{ Make available quality data to client } & 2.96 & & & 0.848 \\
\hline & \% of var. & 35.246 & 22.352 & 20.095 \\
\hline & Cum. \% & 35.246 & 57.597 & 77.692 \\
\hline \multicolumn{5}{|c|}{$\underline{\text { Supplier manaqement }}$} \\
\hline \multicolumn{5}{|c|}{ (Cronbach alpha: 0.88 ; individual item KMO range: 0.656 to 0.903 ; Bartlett's test: 0.000 ) } \\
\hline $\begin{array}{l}\text { Involve suppliers/subcontractors in developing construction } \\
\text { processes }\end{array}$ & 3.36 & 0.796 & & \\
\hline Provide technical assistance to suppliers/subcontractors & 3.23 & 0.792 & & \\
\hline Offer long term relationship with suppliers/subcontractors & 3.89 & 0.753 & & \\
\hline $\begin{array}{l}\text { Place strict requirement on suppliers/subcons to achieve } \\
\text { quality }\end{array}$ & 3.59 & 0.703 & & \\
\hline Rely on few dependable suppliers/subcontractors & 3.37 & & 0.825 & \\
\hline \multirow[t]{3}{*}{ Rate suppliers/subcontractors on delivery performance } & 3.82 & & 0.705 & \\
\hline & $\%$ of var. & 33.246 & 23.783 & \\
\hline & Cum. \% & 33.246 & 57.029 & \\
\hline \multicolumn{5}{|c|}{ Organizational learning } \\
\hline \multicolumn{5}{|c|}{ (Cronbach alpha: 0.94; individual item KMO range: 0.723 to 0.928; Bartlett's test: 0.000 ) } \\
\hline Train employee to understand how company performs & 3.23 & 0.817 & & \\
\hline Employees possess knowledge of basic operation & 3.36 & 0.814 & & \\
\hline Encourage employee learn to improve skill & 3.50 & 0.786 & & \\
\hline Develop environment for on-the-job training & 3.39 & 0.705 & & \\
\hline Encourage personal mastery & 2.98 & & 0.861 & \\
\hline Encourage mental modelling & 3.05 & & 0.794 & \\
\hline Use of systems thinking & 3.05 & & 0.774 & \\
\hline Reward innovation that leads to organizational learning & 3.04 & & 0.731 & \\
\hline Promote climate of openness & 3.48 & & & 0.817 \\
\hline \multirow[t]{3}{*}{ Continuously renew business and construction processes } & 3.27 & & & 0.811 \\
\hline & \% of var. & 23.892 & 21.628 & 20.963 \\
\hline & Cum. \% & 23.892 & 45.520 & 66.483 \\
\hline
\end{tabular}




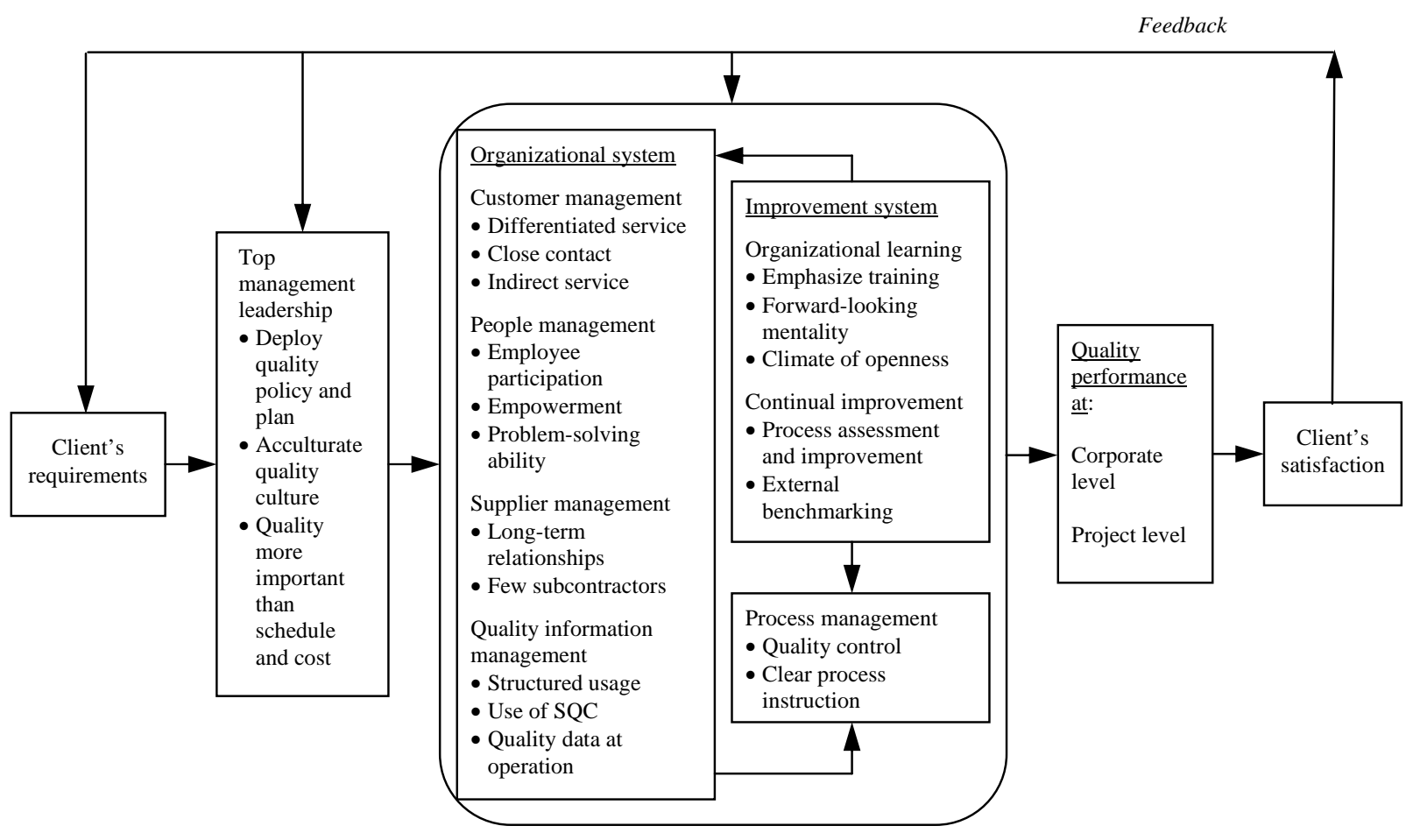

Fig. 1. A framework for TQM implementation 